\title{
O MERCADO DE ALUGUEL NAS FAVELAS CARIOCAS E SUA REGULARIZAÇÃO NUMA PERSPECTIVA HISTÓRICA
}

\author{
RAFAEL SOARES GONÇALVES \\ Pontifícia Universidade Católica do Rio de Janeiro
}

A informalidade do acesso ao solo urbano e a autoconstrução da moradia foram, sem dúvida, alguns dos fatores-chave para manter os custos de reprodução da mão-de-obra, no Brasil e no Rio de Janeiro, os mais baixos possíveis. As favelas sempre foram associadas à ilegalidade, $\mathrm{o}$ que historicamente justificou a ausência de investimentos públicos nesses espaços, permitindo-nos evocar também, para o caso das favelas cariocas, a noção de dupla espoliação urbana desenvolvida por Kowarick (1993) para o caso da expansão da periferia de São Paulo. A tolerância dos poderes públicos para com a formação e a expansão desses espaços tornou-se uma prática pautada na lógica do favor sem, no entanto, que tal prática conduzisse a um reconhecimento de fato desta realidade no seio da pólis.

A construção de um conceito jurídico da favela (Gonçalves, 2010), que associou esses espaços à ilegalidade ao mesmo tempo urbanística e imobiliária, reforçou as representações sociais negativas das favelas e de seus habitantes. Essas representações não davam conta da complexidade social e jurídica desses espaços. Ora, não existe a favela, mas uma miríade de favelas exibindo, cada uma, um diversificado dinamismo econômico, uma acentuada estratificação social e uma diversidade de estatutos fundiários. Ainda que inúmeros autores, desde os anos 1960, tenham destacado os aspectos heterogêneos, atomísticos e dinâmicos das favelas (SAGMACS, 1960; Medina, 1969; Silva, 1967; Parisse, 1970), as representações sociais negativas e simplificadoras das favelas pouco mudaram, e continuam a associar, sistematicamente, as favelas a todas as formas de ilegalismos: do fundiário ao narcotráfico.

Estas representações destacam, cada vez mais, as transformações sociais em andamento nas favelas, aliás, muito visíveis em seus aspectos exteriores: a presença de construções de vários andares, a paulatina instalação de serviços públicos (ainda de qualidade duvidosa), assim como o forte desenvolvimento econômico do comércio e do mercado imobiliário local. Apesar da aparência geralmente inacabada das construções, as 
favelas não apresentam mais o aspecto provisório e precário característico dos seus primeiros tempos. A despeito de algumas ameaças, e eventualmente de algumas remoções em menor escala, recentemente realizadas pela prefeitura, as favelas se consolidaram definitivamente na paisagem urbana carioca.

Embora a expansão atual do mercado imobiliário nas favelas se constitui, como o constata Pedro Abramo (2009: 6), a partir de uma lógica da necessidade, trata-se de um mercado extremamente dinâmico. Reproduz-se, frequentemente, a ideia de que a expansão do mercado imobiliário nestes espaços, sobretudo o de aluguéis, toma proporções incontroláveis nos dias atuais, contribuindo para uma expansão descontrolada das favelas. Ora, poucos trabalhos científicos se concentraram na realidade imobiliária nas favelas. ${ }^{1}$ Sem pretender esgotar a questão, este artigo visa a colocar, numa perspectiva histórica, a importância desempenhada pelo mercado de aluguel na expansão das favelas, bem como na formulação de políticas públicas. Embora sejam raros e geralmente pouco confiáveis os dados históricos sobre tal mercado, é possível constatar que não se trata de uma realidade recente. Muito pelo contrário, esta situação é, desde os meados do século XX, um problema público (Gusfield, 1981) no Rio de Janeiro, que mobilizou autoridades municipais, estruturas associativas locais, legisladores e os próprios habitantes das favelas. Este trabalho abordará, inicialmente, a presença de contratos de locação nas primeiras favelas, ainda no fim do século XIX. Ele se focalizará, posteriormente, no processo de criminalização da cobrança dos aluguéis nas favelas, a partir do Código de Obras de 1937. Ele analisará, enfim, as questões suscitadas pelo mercado do aluguel, no contexto dos projetos de regularização fundiária a partir dos anos 1980.

\section{I - A cobrança dos aluguéis e as origens das favelas no final do século XIX}

Desde o fim do século XIX, as favelas são associadas à ilegalidade e à marginalidade. Diante das medidas higienistas de erradicação dos cortiços e às diferentes reformas urbanas das primeiras décadas do século $\mathrm{XX}$, os favelados teriam pouco a pouco ocupado os terrenos vazios, principalmente aqueles situados nos morros próximos ao Centro da Cidade. Ora, se é incontestável que uma grande parte das favelas se estruturou a

${ }^{1}$ Uma dessas exceções é incontestavelmente o trabalho pioneiro do economista Pedro Abramo. 
partir da ocupação dos terrenos abandonados na cidade, o processo de formação das primeiras favelas foi, na verdade, muito mais complexo, e não se resumiu simplesmente a essas ações. Amplamente difundida, a história, daquela que é considerada como a primeira favela da cidade, revela que os soldados provenientes de Canudos se instalaram no morro da Providência com o consentimento do Exército. Este mesmo consentimento das autoridades militares permitiu, igualmente, o surgimento da favela de Santo Antônio (Gonçalves, 2010: 37). Em suma, esses primeiros habitantes só permaneceram ali em virtude do apoio ativo das autoridades militares. Da mesma forma, como afirma Vaz (1988: 48-50), inúmeras favelas foram formadas por iniciativa dos próprios donos de terrenos. É o caso, especialmente, da favela da Providência, após a erradicação do cortiço Cabeça de Porco, em 1893. Para escapar ao controle higienista, os proprietários de cortiços continuaram suas atividades em áreas dos morros, alugando o solo ou os casebres. De fato, as primeiras favelas se assemelhavam muito aos cortiços da época.

Inúmeras fontes históricas revelam a complexidade do acesso à moradia nas primeiras favelas da cidade, o que parece demonstrar que a identificação sistemática dos favelados como invasores é errônea. Quando da reforma urbana do prefeito Pereira Passos (1902-1906), o processo de ocupação dos morros do Centro da Cidade se intensificou. Everardo Backheuser, engenheiro da prefeitura naquela época, afirmava que "os operários laboriosos que a falta ou a carestia dos cômodos atira para esse logares altos, onde se gosa de uma barateza relativa e de uma suave viração que sopra continuamente. Dulcidificando a rudeza da habitação." (Backheuser, 1906: 111). Embora tendo igualmente afirmado que o prefeito Pereira Passos já estava com os olhos voltados para as favelas e que medidas seriam incessantemente postas em prática para demolir essas construções, sua descrição das favelas não consegue esconder, sob um discurso tipicamente higienista, a tolerância da prefeitura no que concerne à expansão das favelas. A haussmannização da cidade, no início do século $\mathrm{XX}$, desalojou milhares de pessoas e as favelas tornaram-se, na medida do possível, uma das soluções precárias para o problema habitacional do Rio de Janeiro. As reformas urbanas, aliada às medidas higienistas contra os cortiços, reduziram radicalmente a oferta de moradias e, consequentemente, conduziu ao aumento dos preços dos aluguéis. Se os operários procuravam as partes mais altas dos morros era, em parte, por causa dos aluguéis mais baratos lá oferecidos. A reportagem do jornal Correio da Manhã, de 02 de junho de 1907, sobre o morro da Babilônia expõe igualmente a prática habitual de aluguel de casebres nas favelas, no 
início do século passado. Perguntado sobre a existência de aluguel no morro, o ex-soldado João Carlos de Andrade, declarou na ocasião:

“Alugué, uai! A gente não paga nada: o morro é do governo.
Lá p'ra baixo, sim, é d'um inglez que aluga, mas d'água p’ra
cima, como isto já teve baterias, é assim como um veterano,
é militá reformado. A gente chega, escoie um canto, finca os
esteio, barreia e fica morando.”

Em suma, a leitura desta reportagem nos permite concluir que a ocupação do solo não era, seguramente, a única forma de se conseguir uma moradia nas primeiras favelas. Esta realidade era, aliás, bastante conhecida no Rio de Janeiro durante as primeiras décadas do século XX, conforme demonstra as linhas abaixo do escritor Benjamim Constallat. Apesar de reafirmar as representações negativas das favelas, este autor reconhecia, em 1924, a presença de um mercado de aluguel de barracos nas favelas:
« Não atingida pelos regulamentos da prefeitura e longe das vistas da polícia. Na Favela ninguém paga impostos e não se vê um guarda civil. Na Favela, é a lei do mais forte e do mais valente. A navalha liquida os casos. E a coragem dirime todas as contendas (...). Na Favela, não há divórcios, porque ninguém se casa. Não se fazem contratos. Não há inquilinos, nem senhorios. Não há despejos. Se o inquilino é mais forte do que o senhorio, o aluguel nunca é pago. Se o senhorio for mais valente, então, sim, a casa é paga, pontualmente, todos os começos do mês. É a lei do inquilinato da Favela! » (Constallat, 1924, p.35-37).

Apesar do testemunho de Constallat sugerir que os regulamentos municipais não atingiam às favelas, alguns indícios parecem demonstrar que a ocupação dos morros não apenas era tolerada, mas também reconhecida pelos poderes públicos nesse período. O trecho abaixo da escritura, que registrou, em 26 de janeiro de 1928, a locação de barracos situados na favela da Mangueira, demonstra que, em certos casos, a cobrança de aluguéis era oficialmente reconhecida nas favelas.

"Arrendamento de barracões no lote 17 da rua Visconde de Niterói, Estação Mangueira, por D. Julieta de Medeiros Lobato, na qualidade de mãe do menor Décio José. (...) proprietário da maior parte do lote dezessete (...) onde existem vários barracões incorporados ao solo, levantados na vigência do contrato de arrendamento constante da escritura 
de 11 de abril de 1905 (...) pela presente escritura (...) dar em arrendamento ao outorgado Jacintho Pereira Frade alguns desses barracões, (...) assim discriminados : a) barracão dando frente para a rua Visconde de Niterói, sem numeração própria, antigo 166 e hoje arbitrariamente conhecido pelo número 290, sendo de tijolo e coberto de telhas, medindo nove metros e cincoenta centímetros de frente para aquela rua, por onde tem quatro portas e três ao lado, dando estas para a travessa Saião Lobato ; b)dois barracões aos fundos (...) c)um barracão mais adiante na mesma travessa, com uma porta, arbitrariamente conhecido pelo número dezesseis (...) d) um barracão arbitrariamente conhecido pelo número dezoito (...) e)outro barracão, conhecido pelo número [?] (...) f) um grupo de quatro outros barracões aos fundos, na dita travessa, tendo cada um deles porta e janela e divididos em sala e cozinha sendo assoalhadas as salas de cada um, cobertos de telha de canal, na parte dos fundos cobertos de telha de zinco, medindo o supracitado grupo treze metros de frente por nove metros de fundos (...). O prazo de arrendamento será de cinco anos (...) o aluguel será de seis contos e trezentos e sessenta mil reis anuais pagável, porém, por prestações mensais de quinhentos e trinta mil réis". ${ }^{2}$

Mesmo sabendo da dificuldade em afirmar se o exemplo da escritura supracitada se repetiu com frequência em outras favelas, é possível identificar que qualquer medida voltada para o controle da expansão das favelas deveria necessariamente abordar a prática do aluguel nesses espaços. Um dos meios de se manter o aspecto provisório e precário das favelas era justamente recusando toda e qualquer apreciação judicial dos contratos de locação no interior das favelas. Além de proibir novas construções e a reforma daquelas já existentes nas favelas, o Código de Obras de 1937 (Decreto Municipal $\mathrm{n}^{\circ} 6000$ de $1^{\circ}$ de julho de 1937) procurou justamente combater a cobrança de aluguéis pelos proprietários de terrenos onde se situavam as favelas. O que demonstra, uma vez mais, que esta realidade era bastante difundida naquela época, a ponto de

2 Arquivo Nacional (AN): microfilme no. 010.169-79. (Citado por Silva, 2005, p.102-103). Conforme abordado por Maria Laís P. da Silva, esse documento foi posteriormente considerado ilegal já que, como demonstra o artigo do Jornal do Brasil, de 23 de junho de 1933, aqueles terrenos pertenciam à União Federal, e não à Sra. Julieta de Medeiros Lobato. Para dirimir o problema, o próprio Inspetor Regional da Diretoria do Patrimônio queria até mesmo propor ao Ministro da Economia a celebração de um contrato de locação com os moradores da favela da Mangueira. 
estimular as autoridades municipais a inserir nesse código medidas para desencorajar tal prática nas favelas:

«Artigo 349: A formação de favelas, isto é, de conglomerados de dois ou mais casebres regularmente dispostos ou em desordem, construídos com materiais improvisados e em desacordo com as disposições deste decreto, não será absolutamente permitido.

$\S 1^{\circ}$ - Nas favelas existentes é absolutamente proibido levantar ou construir novos casebres, executar qualquer obra nos que existem ou fazer qualquer construção.

$\S 2^{\circ}$ - A Prefeitura providenciará por intermédio das Delegacias Fiscais, da Diretoria de Engenharia e por todos os meios ao seu alcance para impedir a formação de novas favelas ou para a ampliação e a execução de qualquer obra nas existentes, mandando proceder sumariamente à demolição dos novos casebres, daqueles em que fôr realizada qualquer obra e de qualquer construção que seja feita nas favelas.(...)

$\S 5^{\circ}$ - Tratando-se de favela formada ou construída em terreno de propriedade particular, será o respectivo proprietário passível, pela infração das disposições do presente artigo e seu $\S 1^{\circ}$, da aplicação de multa correspondente à execução de obra sem licença e com desrespeito ao zoneamento.

$\S 6^{\circ}$ - A multa estabelecida pelo $\S 5^{\circ}$ será aplicada em relação a cada casebre construído ou a cada casebre em que for executada qualquer obra, independente da demolição sumária, cujas despesas serão cobradas do proprietário do terreno, administrativa ou executivamente, sendo neste último caso acrescidas de $20 \%$.

$\S 7^{\circ}$ - Quando a Prefeitura verificar que existe exploração de favela pela cobrança de aluguel de casebres ou pelo arrendamento ou aluguel do solo, as multas serão aplicadas em dobro, observado o que prescreve o $\$ 4^{\circ}$ do artigo 348 , no caso de ultrapassar, o montante da multa a ser aplicada, da importância de dois mil cruzeiros $(\mathrm{Cr} \$ 2.000,00)$.

$\S 8^{\circ}$ - A construção ou armação de casebres destinados à habitação, nos terrenos, pateos ou quintais dos prédios, fica sujeita às disposições deste artigo.

$\S 9^{\circ}$ - A Prefeitura providenciará como estabelece o Título IV do Capítulo deste Decreto para a extinção das favelas e a formação, para substituí-las, de núcleos de habitação de tipo mínimo ». 
As disposições do Código de Obras de 1937 evidenciam a prática do aluguel do solo e/ou de casas nas favelas, bem como o fato de que em vários casos eram os próprios proprietários que haviam tolerado, ou mesmo estimulado, muitas vezes através da cobrança de aluguéis, a favelização de seus terrenos. ${ }^{3}$ Este código acarretou sérias consequências para o quotidiano dos favelados, embora jamais tenha sido plenamente aplicado, ao menos até os anos 1960. Neste contexto, as favelas adquiriram progressivamente, segundo Stephen Conn, um status político-jurídico «sui generis» (Conn, 1968: 51): elas eram toleradas sem serem reconhecidas de fato. Mais do que a aplicação do Código de Obras de 1937, a questão residia, sobretudo, na possibilidade iminente de aplicá-lo. Ora, como afirma Jean Carbonnier (1979: 101): “A lei inaplicada não permanece menos disponível às conveniências do público, e é esta disponibilidade que é sua utilidade essencial. Para esta espécie de leis, a aplicabilidade importa mais do que a aplicação; ela é por si só eficacidade." Este tipo de vazio jurídico constitui uma forma de fronteira simbólica e institucional que define as favelas como espaços ao mesmo tempo à margem e estruturantes da cidade. A despeito dos sinais muito claros de integração social dos favelados à cidade, o espaço definido pelas favelas poderia, ao menos no plano institucional, ser considerado "como estando, antes de tudo, "na" cidade do que sendo "da" cidade." (Parisse, 1970: 199).

\footnotetext{
${ }^{3}$ Em muitos casos, conforme relata a Folha do Povo, de 2 de dezembro de 1948, sobre o caso do Morro do Vintém, muitos senhorios cobravam aluguéis de terrenos que não lhes pertencia: "A Justiça vem novamente de se pronunciar sobre a discutida posse do Morro do Vintém ou do Turano e dos casebres ali construídos. O italiano Emílio Turano que tem influência na polícia civil e que é responsável por distúrbios e até por morte ali verificada, requereu o despejo de Eloy Antero Dias e outro, alegando que o primeiro estava em atraso com os alugueres de uma casa que lhe locara, edificada em terreno de sua propriedade. Julgando improcedente a ação, o Juiz da $12^{\circ}$ Vara Cível, depois de ter mandado realizar uma perícia no local por engenheiros, condenou Turano a pagar dez vezes o valor das custas e mais honorários do advogado do réo por ter agido com simulação e usado de violência na cobrança de alugueres. Salientou o magistrado que o autor dera como sua uma casa que sabia ser de outrem e pretendera achar-se o imóvel dentro do terreno que diz lhe pertencer, quando para tanto precisava de uma ação demarcatória, da qual aliás havia desistido, naturalmente por carência de direitos.
} 


\section{II - A criminalização do recebimento de aluguel nas favelas a partir dos anos 1940}

A partir do governo Vargas, a questão do aluguel toma um espaço central no contexto político de exceção da Segunda Guerra Mundial. Na intenção de assegurar condições propícias à acumulação do capital, sobretudo industrial, Vargas procurou abrir um canal de negociação e tutela com e sobre as classes operárias, sob a égide do Ministério do Trabalho, Indústria e Comércio. A fim de atenuar o aumento do custo de vida, o governo Vargas instaura uma série de concessões no plano social, dentre elas, a instauração do congelamento dos aluguéis a partir de 1942. Esta medida tornou-se um dos pilares do regime populista de Vargas e foi mantida mesmo após o fim da Guerra. Obviamente que, ao longo dos anos, o Estado fez alguns ajustes no valor dos aluguéis, mas estes índices permaneceram bastante inferiores à inflação. O congelamento só terminou definitivamente após o Golpe Militar de 1964, no contexto das medidas liberalizantes do novo regime visando acelerar a circulação do capital imobiliário.

Ainda que muito popular, esta medida agravou, indiretamente, segundo Nabil (1988), a crise habitacional, pois acarretou uma redução dos investimentos para o mercado de aluguéis, multiplicou os processos de despejos e acabou estimulando a expansão de um mercado imobiliário informal, constituído, paulatinamente, para contornar as restrições impostas pela rígida legislação do inquilinato. Ela provocou igualmente a fuga dos capitais para outros setores econômicos, tais como a indústria e a construção civil, ainda mais pelo fato que o controle de aluguéis reduziu inicialmente os custos da reprodução da força de trabalho, oferecendo uma grande vantagem para esses setores, necessitados de uma vasta mão-deobra (Bonduki, 1988: 77).

De fato, o congelamento dos aluguéis, tornando as moradias raras e mais caras, favoreceu o recurso à favela como uma solução à penúria habitacional sofrida por uma grande parte da população. Como constata Nabil Bonduki, o Estado, ao inaugurar a produção subvencionada de moradia social por intermédio dos Institutos de Aposentaria e Pensão (IAP's), penalizando consideravelmente os proprietários urbanos e tolerando a expansão das favelas e dos loteamentos irregulares nos subúrbios da cidade agiu, de modo consciente ou não, no sentido de reduzir o custo da reprodução da força de trabalho, estimulando indiretamente os setores industrial, da construção civil e da promoção imobiliária (Bonduki, 1996: 837). 
Neste contexto, era certamente vantajoso para os inquilinos poderem assinar um contrato de locação, sob a proteção de uma legislação que lhes era favorável. Durante os anos em que esta legislação permaneceu em vigor (1942-1964), os favelados procuraram frequentemente conquistar e manter a condição de inquilinos, como foi o caso, por exemplo, do projeto dos Parques Proletários Provisórios. Este projeto reassentou em torno de 4.000 favelados, no início dos anos 1940, em construções provisórias de madeira no intuito de urbanizar, no próprio local, as favelas onde viviam, o que, aliás, nunca foi feito. Esses parques, bem localizados na cidade, rapidamente se degradaram, a tal ponto que o recenseamento nacional de 1950 já considerava oficialmente o Parque Proletário $n^{\circ} 1$, aquele situado no bairro da Gávea, como mais uma favela da cidade.

Os moradores desses parques pagavam um aluguel modesto ao governo, o que conferia um aspecto legal às suas moradias. Em decorrência da valorização dos terrenos onde alguns desses parques se situavam, o governo, sob um discurso demagógico, interrompeu a cobrança dos aluguéis, privando assim esses moradores da sua condição de inquilinos, possibilitando, desta forma, a hipótese de expulsá-los. O artigo do Diário de Notícias, de 11 de fevereiro de 1953, mostra claramente que os moradores compreendiam perfeitamente os objetivos ocultos desta decisão da prefeitura: «Não acreditamos, pois que o governo sem cobrar os ínfimos alugueres possa nos dar um melhor conforto: acreditamos até que isto seja a melhor maneira da extinção dos Parques. » (Citado por Oliveira, 1981: 53).

Nos anos 1950, tanto os proprietários de terrenos quanto os inquilinos utilizaram sistematicamente os benefícios que a posição de proprietário e/ou inquilino lhes conferia. ${ }^{4}$ De fato, como constata Maria Laís Pereira da Silva, quando a situação jurídica e política era claramente desfavorável aos favelados nos inúmeros conflitos fundiários, que explodiram durante os anos 1950, estes procuravam estabelecer vínculos

${ }^{4}$ Os Estatutos da Sociedade Civil Associação Pro-Melhoramentos da Vila do Vintém, fundada em 27 de setembro de 1947 (ver Arquivos do Estado do Rio de Janeiro, fundo DPS, notação $n^{\circ}$ 1250) já faziam alusão à condição de inquilino de certos moradores, reivindicando, no entanto, o direito de todos de obter a propriedade de suas moradias: "Artigo $2^{\circ}$ - A Sociedade ora constituída tem como fim congregar todos os ocupantes de terras na referida "Vila do Vintém", quer sejam proprietários das benfeitorias, quer locatários, para os seguintes objetivos: a) Defender o direito de todos contra terceiros que pretendam turbar a posse; b) Obter que todos passem a ser proprietários das benfeitorias, adquirindo-as, pelo justo valor; c) Obter que a prefeitura os reconheça como ocupantes e lhes dê em aforamento a referida área; (...). 
jurídicos com o pretenso proprietário do terreno, pagando-lhe, por exemplo, um aluguel, o que conferia um caráter mais legal aos seus lares, dificultando, por consequência, possíveis despejos judiciais (Silva, 2005: 121). Por outro lado, os pretensos proprietários dos terrenos permitiram muitas vezes a própria ocupação de suas áreas. E, como reconhece José Henrique da Silva Queiroz, responsável pela repartição municipal encarregada de deter a proliferação das favelas, vários proprietários « impedem a ação de nosso serviço, porque incentivam a proliferação que, a eles, interessa, pois recebem aluguéis de barracões, etc. »5

A despeito da ausência de projetos públicos de erradicação em massa das favelas nos anos 1950, algumas dentre elas tiveram suas populações erradicadas para permitir a realização de grandes intervenções urbanas, como foi o caso da favela de Santo Antônio, arrasada, a partir de meados da década de 1950, junto com o morro que ocupava desde o século XIX. Nessa época, aliás, apesar das raras operações de remoção, os favelados eram submetidos a fortes tensões por causa dos inúmeros conflitos judiciários devidos, entre outros motivos, ao não pagamento dos aluguéis. Esta situação provocou tal nível de tensão política que uma lei federal foi promulgada, a «lei das favelas» (lei $\mathrm{n}^{\circ} 2.875$, de 19 de setembro de 1956), destinada a congelar temporariamente os despejos judiciais. Essa lei previu, além da concessão de apreciáveis subvenções públicas a diferentes projetos de construção de habitações populares no Brasil, a proibição de qualquer medida de despejo de favelados durante dois anos, ${ }^{\circ}$ e a preservação de suas moradias até que viessem a se beneficiar de projetos públicos de construção de casas populares:

Art. $5^{\circ}$ Durante o prazo de 2 (dois) anos, a contar da data da publicação desta lei, não será executado nenhum despejo contra moradores de favelas situadas no Distrito Federal.

Art. $6^{\circ}$ É assegurada aos atuais moradores de favelas a permanência nas suas habitações, no caso de não serem beneficiados com as

\footnotetext{
${ }^{5}$ Jornal Diário de Notícias, de 7 de outubro de 1955.

${ }^{6}$ Quando dos debates legislativos, o deputado Bruzzi Mendonça explicou a importância desse período de dois anos: «De nada valeria a urbanização dos logradouros denominados favelas, se ela fosse procedida de um despejo que os expurgasse da maioria de sua população. Visa, pois, a primeira emenda garantir os direitos dos atuais ocupantes das favelas, concedendolhes uma relativa estabilidade no período de construção e de organização dos conjuntos residenciais a serem edificados com o presente crédito. » Deputado Bruzzi Mendonça. Sessão de 23 de janeiro de 1956. Anais da Câmara dos Deputados (1955/1956), vol.7, IBGE, 1956, p.291.
} 
casas construídas com os créditos especiais de que trata a presente lei.

Por outro lado, essa lei afetou o mercado imobiliário nas favelas, pois declarou implicitamente a ilegalidade da locação dos barracos. Ora, a despeito dos abusos dos supostos latifundiários das favelas - apelidados pela imprensa da época como «os tubarões das favelas» - a condição de inquilino conferia um aspecto mais legalizado às favelas e, aos favelados, oferecia a possibilidade de reivindicar certos direitos, minimizando a qualidade "sui generis" da natureza jurídica desses espaços. Evidentemente, esta iniciativa não desencorajou as práticas imobiliárias nas favelas, que continuaram a se multiplicar informalmente. Desde então, instaurou-se um debate jurídico sobre a regulação deste mercado imobiliário próspero e lucrativo. Os tribunais aplicaram seguidamente a legislação do inquilinato aos barracos e casebres situados nas favelas da cidade (Espínola Filho, 1957: 40). Julgando os despejos judiciais de favelados por causa de falta de pagamento de aluguéis, alguns juízes acabavam conferindo certo reconhecimento jurídico às favelas. É o que demonstra, por exemplo, o trecho da decisão da $1^{\mathrm{a}}$ Câmara Civil da Corte do Distrito Federal, de 7 de dezembro de 1953, a seguir:

\begin{abstract}
« Considerando que a ação de despejo foi proposta pela autora na qualidade de moradora no barracão $\mathrm{n}^{\circ} 338$ do morro de Santo Antônio contra locatários de cômodos do mesmo barraco; que a lei nº1.300 se refere à locação de prédio urbano $\left(\operatorname{art.1}{ }^{\circ}\right)$; que a expressão prédio tem o sentido jurídico com o qual é empregado no Código Civil, sentido que é o que tem no vernáculo; que não importa se trate de construção mais ou menos leve, pobre, modesta ou desmontável, aplica-se, sempre, se é urbano o imóvel, a lei n 1.300 ; a habitação do pobre, por modesta que seja, merece a proteção da lei; se há locação de cômodos do barracão e a locadora alega não estarem sendo pagos os alugueres, a ação própria para a desocupação é a de despejo, não cabendo ação possessória; considerando o mais que dos autos consta; acordam em dar
\end{abstract}

\footnotetext{
${ }^{7}$ O trecho abaixo, da decisão de um juiz, em 1958, sobre a lei das favelas, demonstra que determinados juízes aceitavam plenamente as atividades imobiliárias nas favelas, a despeito das proibições impostas pelo Código de Obras de 1937, e da lei das favelas: «Seria estranha aceitar que moradias sejam cedidas de forma gratuita por dois anos, durante os quais o proprietário teria assumido todos os custos, observando, inclusive, a ruína e a destruição de sua propriedade sem poder defender seu patrimônio." (Citado por Conn, 1968:63).
} 
provimento ao agravo $\mathrm{n}^{\circ} 4.408$, para que, reformando o despacho agravado, se prossiga nos demais termos do processo da ação de despejo6». ${ }^{8}$

Apesar da apreciação favorável de alguns juízes em relação às demandas dos proprietários de imóveis nas favelas, as autoridades municipais procuraram consolidar sistematicamente a condição de ilegalidade da locação nas favelas. O Serviço Especial de Recuperação das Favelas e Habitações Anti-Higiênicas (SERFHA) promulgou, em 25 de junho de 1959, uma circular que reforçava a proibição dos aluguéis nas favelas do Rio de Janeiro:

«Visando coibir a especulação e o abuso que se efetiva contra a população pobre desta cidade, residente em nossas favelas, esclarece a SERFHA que não é permitida a cobrança de alugueres de barracos devendo ser suspenso todo e qualquer pagamento que venha sendo feito a qualquer título a exploradores que financiam ou promovem a construção dessas habitações, sem a devida licença dos órgãos competentes.

O Poder Público não está obrigado a reconhecer qualquer direito que decorra de uma construção clandestina e que se efetiva contra as leis que regulam o assunto.

Por outro lado, o SERFHA informa que está à disposição das vítimas desses exploradores, através do seu Serviço de Assistência Judiciária e Auxílios para prestar a assistência que se fizer necessária em defesa de seus direitos, no Posto de atendimento, sito à Avenida Antônio Carlos (aterro), diariamente, das 8 às 17 horas."

Esta circular influenciou algumas decisões judiciais. O juiz Irineu Jofilly, da $6^{\mathbf{a}}$ Câmara Civil, por exemplo, impediu a expulsão de favelados que não pagaram seus aluguéis. Citamos, a este propósito, o artigo do jornal Diário de Notícias, de 8 de agosto de 1959: «Ao fulminar a pretensão do « tubarão das favelas », o juiz prestigiou a portaria do coordenador do Serviço Especial de Recuperação de Favelas e Habitações Anti-higiênicas (SERFHA), que, proibiu a cobrança de alugueis em favelas ». A posição deste juiz não era, no entanto, consensual. O juiz Antônio Soares Pinho, da 14 ${ }^{\mathrm{a}}$ Câmara Civil, por sua vez, ao aceitar

\footnotetext{
${ }^{8}$ Des. Romão Lacerda, rel. Coelho Branco e Faustino Nascimento; Diário da Justiça, de 26 agosto de 1954, p.2.768. (Citado por Espínola Filho, 1957: 1051).

${ }^{9}$ Citado pelo jornal Diário Carioca, de 26 de junho de 1959.
} 
as alegações de um suposto proprietário de terras situadas na favela da Rocinha, decretou a expulsão dos moradores, a despeito da circular do SERFHA. ${ }^{10}$ Como muitos favelados haviam deixado de pagar seus aluguéis imediatamente depois da expedição dessa circular, vários proprietários apelaram para a violência para exigir seus pagamentos ou entraram com ações judiciais, o que aumentou consideravelmente as tensões sociais. Segundo a mesma reportagem do Diário de Notícias, de 8 de agosto de 1959, mais de 100 proprietários se rebelaram contra a portaria do SERFHA e 79 ações de despejo já estavam sendo movidas pelos pretensos proprietários de favelas.

Esta proibição foi reforçada, ainda mais, pelas autoridades locais. A promulgação do decreto do Estado da Guanabara $n^{\circ} 374$, de 24 de fevereiro de 1961, não somente reforçou estas disposições, como também proibiu todas as transferências de barracos nas favelas. Mesmo os proprietários legítimos dos terrenos onde se localizavam as favelas deviam previamente apresentar seus títulos de propriedade ao SERFHA, para poderem obter a permissão de receberem os aluguéis correspondentes ao solo. Dificultando toda e qualquer apreciação judiciária suscetível de provocar um reconhecimento de fato das favelas, este procedimento consolidou ainda mais o caráter ilegal das mesmas. O preâmbulo do supracitado decreto anunciava:

É necessário coibir a especulação que se pratica contra a população desprotegida residente nas favelas deste Estado. Cobram-se taxas às vezes elevadas, pela ocupação de terrenos de propriedade duvidosa, e aluguéis, descabidos pelo uso de barracos e outras construções clandestinas A lei federal $n^{\circ} 2.875$, de 19 de setembro de 1956, assegurou a permanência dos moradores de favelas nas respectivas habitações. Por outro lado, é evidente que o Poder Público não está obrigado a reconhecer qualquer direito decorrente de construções clandestinas.

A precariedade do aspecto jurídico das construções nas favelas impedia, segundo Stephen Conn (1968: 100-101), a apreciação do poder judiciário quanto a possíveis direitos decorrentes de atividades imobiliárias nas favelas, mesmo quando se tratava de casas sólidas, de tijolos. Stephen Conn sustenta que desde a promulgação da «lei das favelas», em 1956, as construções nessas áreas foram consideradas, cada vez mais, como uma realidade provisória, passíveis de serem destruídas assim que os poderes públicos construíssem casas populares para substituí-las. Fato reforçado pelo conteúdo do artigo $4^{\circ}$ do decreto $\mathrm{n}^{\circ} 374$, que não reconhecia direito

${ }^{10}$ Ver o Jornal Ultima Hora, de 26 de novembro de 1959. 
algum em relação a atos tendo como objeto os "barracos clandestinos" nas favelas.

Como já havíamos constatado acima, várias favelas se desenvolveram com a concordância, e até mesmo com o apoio, dos proprietários. Alguns destes proprietários chegaram ao ponto de celebrar contratos de aluguel com os favelados, estabelecendo uma relação jurídica com estes. Entretanto, a qualquer instante, eles podiam suspender a cobrança dos aluguéis, a fim de criar uma situação jurídica favorável à expulsão dos inquilinos. Há fortes indícios, segundo Maria Laís Pereira da Silva (2005: 101), de que cerca de 40\% das favelas, antes de 1964, se desenvolveram graças a certo tipo de autorização prévia, concedida pelos ditos proprietários ou, no caso de terrenos públicos, por funcionários.

Enfim, apesar dos poucos dados existentes sobre o mercado imobiliário informal nas favelas, determinados autores destacaram, naquela época, o seu desenvolvimento, mostrando que não se tratava de uma realidade marginal. O médico sanitarista Victor Tavares de Moura afirmou, em 1957, conhecer um indivíduo que havia abandonado suas atividades de construção de arranha-céus para levantar barracos nas favelas, devido aos benefícios que ele poderia obter com esta atividade. Ele citava igualmente o caso dos irmãos Modesto, da favela do Cantagalo, que possuíam 190 barracos alugados no morro, bem como 52 biroscas. ${ }^{11}$ Lucien Parisse, por outro lado, afirmava que 13,7\% dos habitantes das favelas, nos anos 1960, pagavam aluguéis do solo ou da casa (Parisse, 1970: 162).

A criminalização do mercado da locação contribuiu para reforçar a condição precária das favelas, contribuindo para legitimar a política de

${ }^{11}$ Discurso de Victor Tavares de Moura sobre as favelas, em 8 de janeiro de 1957. Arquivos da Fundação Oswaldo Cruz (FIOCRUZ). Fundo: Victor Tavares de Moura VT/PI/19570108.

Alguns jornais da época fizeram uma grande campanha contra os promotores imobiliários das favelas, chamados de "tubarões das favelas". Tais reportagens citavam frequentemente o nome dos proprietários, conforme demonstra o trecho da reportagem abaixo do Jornal Diário de Notícias, de 8 de agosto de 1959 : "Xisto dos Santos, com 115 barracos na favela do morro São João; Fábio Kelly de Carvalho, 220 barracos na favela D. Francisca; Elias Mansur, com 200 barracos na favela do Barro Vermelho; Elias Kalil, com 120 barracos no Barro Vermelho; P. Pinheiro, com 300 barracos na Mangueira; Sr. Riso, com 200 barracos na Cachoeirinha; Angela Rodrigues de Souza, com 68 barracos no Morro da Formiga; Henrique Salgueiro Filho, com 20 barracos na Favela Euclides da Rocha; Adelina Cabral e Rosa dos Santos, com 50 barracos cada uma, na ladeira do Tabajara e Curral das Éguas; Maria Rosa de Oliveira, com 50 barracos, na favela da Leopoldina." 
remoção, que resultou na expulsão de 140 mil favelados para locais esmos e distantes da metrópole, entre os anos de 1962 e 1975. A abertura democrática pôs fim à política de erradicação das favelas e destacou as iniciativas públicas para urbanizar e regularizar esses espaços. Ainda que a cobrança dos aluguéis seja sempre criticada, e mesmo desencorajada, nos dias atuais, os projetos públicos de regularização fundiária, como veremos a seguir, acabaram gradualmente reconhecendo esta realidade.

\section{III - Aluguéis e as políticas de regularização fundiária a partir dos anos 1980}

$\mathrm{O}$ primeiro projeto de regularização fundiária propriamente dito realizado no Rio de Janeiro foi o Cada Família um Lote, da primeira administração de Brizola no Estado do Rio de Janeiro (1983-1986). Anterior às inovações realizadas a partir da Constituição de 1988, este projeto foi pioneiro das políticas de regularização do solo das favelas. A Companhia de Habitação do Estado do Rio de Janeiro (CEHAB) emitia uma promessa de compra e venda aos beneficiários do projeto; após pagarem um financiamento de 48 mensalidades que normalmente não ultrapassavam $10 \%$ do salário mínimo, eles tinham, em tese, o direito de solicitar a redação da escritura definitiva e o seu registro no RGI respectivo (Araujo, 1990: 28). O projeto não impunha qualquer restrição quanto ao uso da propriedade pelos seus beneficiários, mas proibia a comercialização do bem durante o pagamento do financiamento, sob pena de rescisão de pleno direito da promessa de compra e venda. Todavia, esta regra não foi sempre respeitada, e transferências informais das promessas acabaram acontecendo (Araujo, 1988: 74-76). O projeto precisou enfrentar também a questão dos imóveis informalmente alugados. Uma carta da Associação de Moradores da Favela do Jacarezinho, endereçada ao Secretário Estadual de Trabalho e Habitação, datada de 29 de janeiro de 1984, revela as questões sociais relacionadas aos inquilinos (Citado por Araujo, 1990: 29):

\footnotetext{
"Somos totalmente contra a exploração imobiliária; achamos que o Governo deve facilitar a aquisição da casa própria por cada inquilino ou, no caso de não ser possível a solução deste problema, que o Governo assegure que os alugueis não sofram reajustes exorbitantes em função de o proprietário estar com o seu título de propriedade (...). Explicação: existem dentro de nossa comunidade pessoas que possuem inúmeras casas alugadas e que moram em outros bairros. (...) Se o proprietário de dez casas alugadas recebe dez títulos de
} 
propriedade se estará controvertendo o projeto Cada Família um Lote."

De fato o governo, que queria conceder, inicialmente, um só título por família, foi obrigado a intervir nos conflitos entre proprietários e inquilinos, a fim de que estes últimos pudessem adquirir suas residências. Se os proprietários não aceitassem este acordo, a CEHAB não entregaria o título de propriedade (Araujo, 1988: 29). A questão dos inquilinos causou inúmeros problemas, e estes rapidamente se mostraram desinteressados em relação ao projeto, não apenas devido ao fato de que eles não dispunham do capital necessário para a compra das moradias onde residiam, mas também pelo fato que alguns proprietários, concuminados com grupos criminosos locais, impunham-lhes sistematicamente a lei do silêncio, já que não admitiam perder seu capital (Araujo, 1988: 30-31).

A nova ordem urbanística, a partir da Constituição de 1988, procurou combater uma possível concentração imobiliária, após a implantação de projetos de regularização fundiária. Determinados instrumentos jurídicos, como a Usucapião especial urbana, a concessão especial para fins de moradia, ou então, mais recentemente, a legitimidade da posse, ${ }^{12}$ reconhecem direitos fundiários somente aos ocupantes de imóveis. Estes não podem ser nem proprietários, nem concessionários de outros imóveis. Esta restrição busca atenuar um presumível processo de gentrificação do bairro, após a regularização fundiária, procurando conciliar, ao mesmo tempo, as funções sociais e o valor comercial do bem em regularização. Enfim, a legislação referente à regularização fundiária destacou, assim, a figura do proprietário-ocupante em detrimento daquele que, possuindo diversos imóveis, exerceria a função de promotor imobiliário local. No entanto, essa legislação não responde a realidade dos pequenos

\footnotetext{
12 A usucapião especial urbana permite aos ocupantes de terrenos particulares, que não sejam proprietários nem concessionários de outro imóvel urbano ou rural, adquirirem a propriedade do solo por meio de uma sentença declaratória de usucapião, se habitarem no local por um período superior a cinco anos, se o proprietário não interveio para recuperar o terreno durante este período e com a condição de que a superfície do lote não ultrapasse os 250m2. Quando se trata de terrenos públicos, o ocupante pode reivindicar administrativamente, sob as mesmas condições supracitadas, a concessão especial para fins de moradia junto ao órgão público proprietário do imóvel. A fim de contornar a necessidade de um processo judicial para declarar a usucapião, a lei no 11.977 , de 7 de julho de 2009, instituiu a legitimidade da posse, que reconhece a posse dos ocupantes e simplifica os procedimentos necessários para a regularização urbanística. Ao fim de cinco anos, o ocupante pode transformar seu título de legitimidade de posse em propriedade privada, junto ao registro de imóveis sem precisar da manifestação do poder judiciário.
} 
proprietários, que muitas vezes construíram em suas lajes novas moradias que alugam. Estes, em tese, não poderiam se beneficiar dos instrumentos jurídicos supracitados. ${ }^{13}$

Apesar das disposições legislativas, o projeto de urbanização de favelas, Favela-Bairro, posto em prática a partir de 1995 no Rio de Janeiro, reconheceu a estrutura do mercado imobiliário informal. O ponto 5.1.9.e. do regulamento operacional do Programa de Urbanização de Assentamentos Populares do Rio de Janeiro (PROAP-RIO), que abrangia o Favela-Bairro, definiu, no que diz respeito a questão de indenização das pessoas removidas durante as obras de urbanização, que os inquilinos deveriam receber uma indenização equivalente a três meses de aluguel, além da ajuda para encontrar uma nova residência, enquanto que os proprietários informais deveriam ser plenamente indenizados à altura do valor de suas casas. Ainda que os esforços de titularização do projeto Favela-Bairro tenham sido marcados por um fracasso retumbante, este projeto consolidou definitivamente as favelas no Rio de Janeiro, reconhecendo, aliás, a estrutura interna do mercado de aluguel nesses espaços.

A questão que se coloca sobre o mercado do aluguel é saber se os proprietários locais, alguns deles verdadeiros agentes imobiliários, devem se beneficiar gratuitamente dos esforços públicos para regularizar o solo nas favelas. Em alguns projetos atuais, como o de regularização da favela da Rocinha, no âmbito do projeto federal Papel Passado, apenas os custos referentes ao primeiro título está inserido no projeto ${ }^{14}$ : os que possuem diversos imóveis devem arcar com os custos da regularização, a partir do segundo título. Os inquilinos, por sua vez, não têm voz ativa no processo de regularização, e geralmente nem são recenseados durante o projeto de regularização fundiária.

Há alguns anos, vem ocorrendo uma forte expansão de agentes imobiliários em determinadas favelas da cidade. Gerônimo Leitão (2007) relata, no caso específico da Rocinha, a chegada à favela de investidores externos que decidem investir ali por causa da alta rentabilidade da atividade imobiliária naquela região. Apesar das críticas ao crescimento do

13 É até mesmo possível regularizar a situação de proprietários de diversos imóveis, mas os procedimentos são mais longos e complexos.

14 Os projetos de regularização pleiteiam a gratuidade de justiça aos beneficiários. No entanto, certos juízes recusaram alguns pedidos de gratuidade, alegando que certos favelados não eram necessariamente pobres, sem capacidade de arcar com as custas judiciais. 
mercado informal de aluguel, concentrado - em algumas favelas - nas mãos de alguns poucos proprietários, Pedro Abramo destaca que tal mercado, no Rio de Janeiro, ainda é muito pulverizado, concentrando-se nas camadas mais pobres e nos recém-chegados às favelas, aqueles que ainda não têm como economizar capital para comprar uma casa no interior da favela, nem possuem acesso ao crédito bancário. Segundo este autor, o crescimento do parque imobiliário de aluguéis se explica, em parte, pela informalidade do mercado de trabalho que estimulou uma grande parte dos favelados a expandir ou subdividir sua própria residência para alugá-la (Abramo, 2009: 36/37).

Esta atividade não está cercada de um excessivo formalismo nas garantias exigidas aos novos inquilinos, e oferece flexibilidade na cobrança dos aluguéis, passo fundamental visto a precariedade do trabalho de uma grande parte dos inquilinos. Apesar dos preços exorbitantes dos imóveis em algumas favelas, sobretudo aquelas mais bem localizadas, como a da Rocinha, ainda é mais rentável habitar nesta favela, como demonstra Leitão (2007), do que pagar um aluguel mais barato no subúrbio, mas com os custos e o tempo exorbitante de deslocamento num sistema de transporte completamente ineficiente.

Segundo Pedro Abramo (2009: 41), o mercado informal de aluguel caracteriza-se por uma forte presença de residências de um só cômodo, cerca de $70,1 \%$ do parque de locação das favelas do Rio de Janeiro. É o resultado da subdivisão das residências em várias unidades familiares e/ou da construção vertical de várias quitinetes. Observa-se, assim, um retorno da população para áreas centrais, nas favelas onde as construções verticais se assemelham, em parte, aos antigos cortiços do início do século XX. Além disso, a absorção de novos habitantes nessas favelas na última década, aconteceu, em grande parte, através do mercado de aluguel. Segundo as pesquisas de Pedro Abramo, a porcentagem de inquilinos subiu de 14,8\%, em 2002, para 27,27\%, em 2008 (Abramo, 2009: 35-36). O mercado informal de aluguel pode, todavia, tornar-se um problema, pois ele está tornando ainda mais precário o que já é precário (Abramo, 2009: 43), ao construir moradias cujas condições de habitabilidade são altamente duvidosas. É preciso, todavia, levar em consideração que este mercado cobre uma grande parte do déficit de moradias no Rio de Janeiro, e toda iniciativa de regulamentação deve melhorar as condições habitacionais nas

\footnotetext{
15 Os poderes públicos tiveram que aumentar o valor do aluguel social, de 250 reais para 400 reais, pois o valor anterior não cobria mais os custos do aluguel numa grande parte das favelas do Rio de Janeiro.
} 
favelas sem proibir completamente esta realidade. O retorno de uma criminalização desta atividade seria algo, certamente, ineficaz e desastroso.

\section{Em guisa de conclusão: regularizar o solo sem criminalizar o mercado de locação informal}

As medidas higienistas de destruição dos cortiços e as sucessivas reformas urbanas das primeiras décadas do século XX estimularam a ocupação dos morros da cidade como uma precária solução para a crise habitacional. Inúmeras favelas, aliás, foram constituídas com o consentimento dos pretensos proprietários de terrenos, através do aluguel do solo ou dos casebres aí existentes. O debate acerca dos aluguéis nas favelas tomou uma grande proporção no contexto da legislação do congelamento dos aluguéis (1942-1964). Como vimos, ocorreram inúmeros despejos judiciais pela falta de pagamento dos aluguéis nas favelas. Aceitar esse mercado de locação poderia ter acarretado um reconhecimento de fato das favelas, o que levou a prefeitura a proibir o recebimento de aluguéis nas favelas, afirmando que se tratava de construções clandestinas em terrenos ocupados ilegalmente. Após o fracasso retumbante das políticas de remoção (1962-1975), e no contexto de abertura política do fim dos anos 1970, a questão da urbanização e regularização do solo das favelas entra definitivamente na agenda política. Embora até hoje esses diferentes projetos tenham urbanizado um grande número de favelas, eles avançaram muito pouco quanto à titularização dos terrenos, sem conduzir a um efetivo processo de formalização do mercado local de aluguel.

Enquanto as favelas são ainda associadas, simploriamente, a ocupações de terrenos, e seus habitantes a miseráveis e marginais; a reflexão, em uma perspectiva histórica, do mercado de aluguel nas favelas, demonstra que, desde a sua origem, estas são espaços heterogêneos e extremamente dinâmicos. Se a regularização do mercado de aluguel pode se tornar uma forma de reconhecimento das favelas, o atual crescimento do mercado de aluguel poderia atuar, como já o constatamos, em desfavor das populações mais pobres. Ainda que este mercado represente uma oferta não negligenciável de moradias, o atual laisser-faire contribui apenas para reforçar, a médio prazo, a precarização da habitação e a concentração imobiliária excessiva nas favelas. Sem criminalizar essas atividades imobiliárias, e levando em consideração as particularidades do mercado informal de aluguel, a regulamentação deste mercado mostra-se 
fundamental para assegurar, ao mesmo tempo, o uso social do solo nas favelas e a melhoria da qualidade da habitação nesses espaços.

\section{O MERCADO DE ALUGUEL NAS FAVELAS CARIOCAS E SUA REGULARIZAÇÃO NUMA PERSPECTIVA HISTÓRICA}

Resumo: Este artigo pretende colocar em perspectiva histórica o papel exercido pelo mercado de aluguéis na expansão das favelas, assim como na formulação de políticas públicas. Apesar da ausência de dados sobre este mercado, é possível constatar que não se trata de uma realidade recente. Ao contrário, o mercado de aluguéis é, desde o início do século XX, um problema público no Rio de Janeiro. $\mathrm{O}$ presente trabalho constata, inicialmente, a existência de aluguéis desde o início das favelas. Posteriormente, analisará o processo de criminalização da cobrança de aluguéis a partir do Código de Obras de 1937. Por fim, abordará as questões suscitadas pelo mercado de aluguéis no contexto dos projetos de regularização fundiária a partir dos anos 1980.

Palavras-chave: Favelas, mercado informal de aluguéis, Rio de Janeiro, regularização fundiária, história urbana

\section{THE RENT MARKET IN CARIOCA FAVELAS AND THEIR REGULARIZATION THROUGH AN HISTORICAL PERSPECTIVE}

Abstract: This article intends to put into historical perspective the role exercised by the rent market in the expansion of favelas, as well as in the formulation of public policies. Despite the absence of data about this market, you can see that this is not a recent reality. Unlike, the market rent is, since the early 20th century, a public issue in Rio de Janeiro. The present study notes, initially, the existence of rents from the beginning of the favelas. Later, it will examine the process of criminalizing the collection of rents from the Municipal Code of constructions from 1937. Finally, it will address the issues raised by the rent market in the context of land regularization projects from the years 1980.

Key-words: Favelas, informal rent Market, Rio de Janeiro, land regularization, urban history 


\section{BIBLIOGRAFIA}

ABRAMO, P (2009). Favela e mercado informal: a nova porta de entrada dos pobres nas cidades brasileiras, Porto Alegre, ANTAC.

ARAUJO, Maria Silvia M. de (1988), As práticas de execução do programa cada família, um lote, Dissertação de Mestrado, UFRJ/IPPUR.

ARAUJO, M. S. M. (1990), "Regularização fundiária de favelas - imóveis alugados : o caso do programa 'Cada família um lote' no Rio de Janeiro", Revista de administração municipal, n. ${ }^{\circ} 195,1990$, p.26-35.

BACKHEUSER, E (1906), Habitações populares, Rio de Janeiro, Imprensa Nacional.

BONDUKI, N (1996), "Habitação, Estado e movimento moderno : a ação dos IAP's." In Farret, R. (org.), Anais do $6^{o}$ Encontro Nacional da ANPUR - Modernidade, exclusão e a espacialidade do futuro. Brasilia: ANPUR. pp.836-851.

(1988). Origens da Habitação Social no Brasil. Arquitetura Moderna, Lei do Inquilinato e Difusão da Casa Própria, São Paulo, Estação Liberdade/FAPESP.

CARBONNIER, J (1979). Flexible droit. Textes pour une sociologie du droit sans rigueur, Paris: LGDJ.

CONN, S (1968). "The Squatters' Rights of Favelados", Ciências Econômicas e Sociais. $\mathrm{n}^{\circ}$ 2, pp.50-142.

CONSTALLAT, B (1990). Mistérios do Rio, Rio de Janeiro : Secretaria Municipal de Cultura, Biblioteca Carioca, ${ }^{\circ} 14$.

ESPÍNOLA FILHO, E (1957). Manual do inquilinato no direito civil vigente estudo de toda a legislação brasileira em vigor, inclusive as leis 2.875, de 19 de setembro de 1956 e 3.085, de 29 de dezembro de 1956, Rio de Janeiro, Borsoi.

GUSFIELD, J. R (1981). The culture of public problems : drinking-driving and the symbolic order. Chicago: the university of Chicago Press.

KOWARICK, L (1993). A espoliação urbana. Rio de Janeiro, Paz e terra.

LEITÃO, G (2007). "Transformações na estrutura socioespacial das favelas cariocas: a Rocinha como um exemplo", Cadernos metrópole, $\mathrm{n}^{\circ} 18$, pp. 135-155.

GONÇALVES, R. S (2001). Les favelas de Rio de Janeiro. Histoire et droit. XIX-XX Siècles, Paris : L'Harmattan.

MEDINA, C. A (1969). "A favela como uma estrutura atomística : elementos descritivos e constitutivos." América Latina. n 3, pp.113-136. 
OLIVEIRA, N. S (1981). Parque proletário da Gávea. Uma experiência de Habitação popular. Dissertação de Mestrado, UFRJ.

PARISSE, L (1970). Favelas de l'agglomération de Rio de Janeiro, Thèse de doctorat de 3ème Cycle, Université de Strasbourg.

SAGMACS (1960), "Aspectos humanos da Favela Carioca." O Estado de São Paulo. 8 et 15 Avril 1960. Sao Paulo.

SILVA, L (1967). A. Machado, "A política na Favela." Cadernos Brasileiros. $\mathrm{n}^{\circ} 41, \mathrm{pp} .35-47$.

SILVA, M. L. P (2005). Favelas Cariocas 1930-1945. Rio de Janeiro, Contraponto.

VAZ, L. F (1988). "Do Cortiço à Favela, um lado obscuro da modernização do Rio de Janeiro." In Sampaio, M. R. A. (éd.). Habitação e Cidade. São Paulo: FAU/USP-FABESP, pp.39-52. 